\title{
Spatial compartmentalization of signal transduction in insulin action
}

\author{
Christian A. Baumann and Alan R. Saltiel*
}

\begin{abstract}
Summary
Insulin resistance is thought to be the primary defect in the pathophysiology of type 2 diabetes. Thus, understanding the cellular mechanisms of insulin action may contribute significantly to developing new treatments for this disease. Although the effects of insulin on glucose and lipid metabolism are well documented, gaps remain in our understanding of the precise molecular mechanisms of signal transduction for the hormone. One potential clue to understanding the unique cellular effects of insulin may lie in the compartmentalization of signaling molecules and metabolic enzymes. We review this evidence, and speculate on how PI-3 kinase-independent and -dependent signaling pathways both diverge from the insulin receptor and converge at discrete targets to insure the specificity of insulin action. BioEssays 23:215-222, 2001. ๑ 2001 John Wiley \& Sons, Inc.
\end{abstract}

\section{Introduction}

Diabetes mellitus is a worldwide epidemic, in some ethnic groups affecting over $10 \%$ of the population. Type 1 diabetes, defined by an absolute requirement for administration of exogenous insulin, results from the autoimmune destruction of the insulin-secreting pancreatic $\beta$ cells. Type 2 diabetes usually occurs during adulthood, and is often characterized by a relative resistance to endogenous insulin. The pathophysiology of type 2 diabetes, which accounts for over $90 \%$ of patients with the disease, involves defects in three organ systems that conspire together to produce abnormal glucose and lipid metabolism. While there is some uncertainty

Department of Cell Biology, Parke-Davis Pharmaceutical Research and the Department of Physiology, University of Michigan.

*Correspondence to: Dr. Alan R. Saltiel, Life Sciences Institute, Department of Internal Medicine, University of Michigan School of Medicine, MSRB1, Room 4520, 1150 W. Medical Center Dr., Ann Arbor, Ml 48109-0650. E-mail: saltiel@umich.edu

Abbreviations: CAP, c-Cbl associating protein; EGF, epidermal growth factor; IRAP, insulin-responsive aminopeptidase; GSV, Glut4 vesicle; IRS, insulin receptor substrate; PDGF, platelet-derived growth factor; PDK, phosphoinosotide dependent kinase 1; PIP3, phosphotidylinositol 3,4,5 triphosphate; PKB, PI 3-kinase protein kinase B; PKC, protein kinase $\mathrm{C}$; $\mathrm{SH} 2$, src-homology 2; $\mathrm{SH} 3$, src-homology 3 ; SNARE, soluble $\mathrm{N}$-ethylmaleimide sensitive factor attachment protein; Syn4, syntaxin 4. regarding the primary lesion, or relative importance of different tissues, metabolic defects in liver, peripheral target tissues such as fat and muscle and pancreatic $\beta$ cells all contribute to the syndrome. Insulin resistance, which is defined as a state of reduced responsiveness to normal circulating concentrations of insulin, is now recognized as a characteristic trait of type 2 diabetes, and contributes to abnormalities in all of these tissues.

A number of prospective epidemiological studies across several population groups have indicated that type 2 diabetes progresses over a continuum of worsening insulin action, beginning with peripheral insulin resistance and ending with a loss of insulin secretion. In most patients, insulin resistance can be detected long before the deterioration of glucose intolerance occurs. Insulin resistance is a quite common state, associated with aging, a sedentary lifestyle, as well as a genetic predisposition. The state seems to be fueled by or perhaps to a certain extent the result of obesity. The ensuing dysregulation of carbohydrate and lipid metabolism that occurs as a consequence of insulin resistance further exacerbates its progression. Beta cells of the pancreas normally compensate for the insulin-resistant state by increasing basal and postprandial insulin secretion. At some point, the beta cells can no longer compensate, failing to respond appropriately to glucose. This ultimately leads to the deterioration of glucose homeostasis, and the development of glucose intolerance. Approximately $5-10 \%$ of glucose intolerant patients per year progress to frank diabetes, which continues to worsen as insulin resistance increases. Adipose cells generate more fatty acids, the liver produces more glucose in an unregulated fashion, and the beta cells undergo complete failure, resulting in the late stages of the disease, where high doses of exogenous insulin may be required.

Even in the absence of diabetes, insulin resistance is a key feature of other human disease states. Impaired insulin action coupled with hyperinsulinemia leads to a variety of abnormalities, including elevated triglycerides, low levels of HDL, enhanced secretion of VLDL, disorders of coagulation, increased vascular resistance, changes in steroid hormone levels, attenuation of peripheral blood flow and weight gain. Thus, insulin resistance is often associated with central obesity, hypertension, polycystic ovarian syndrome, dyslipidemia and atherosclerosis. This constellation of symptoms is often referred to as Syndrome X, or Insulin Resistance 
Syndrome. Whether impaired insulin action is directly responsible for all of the symptoms in these patients remains unclear. However, the broad prevalence of insulin resistance, and its association with profound metabolic abnormalities is widely accepted.

Insulin is the most potent anabolic agent known, promoting the synthesis and storage of carbohydrates, lipids and proteins, and inhibiting their degradation and release back into the circulation. Insulin maintains glucose homeostasis by stimulating glucose uptake, utilization and storage in muscle and adipose tissue, and inhibiting glucose output from liver. The hormone also plays an important role in regulating lipid homeostasis, stimulating lipogenesis in fat and liver, and inhibiting lipolysis in fat and muscle. While the underlying cause of insulin resistance remains unknown, investigations have focused on defects in signaling and metabolic pathways. Studies in type 2 diabetic patients have shown that the primary defect in insulin action lies in the regulation of glucose transport in adipose and muscle. This process is mediated by the insulin-stimulated glucose transporter, Glut $4 .{ }^{(1)}$

Insulin action is initiated through the binding to and activation of its tyrosine kinase receptor. At the cellular level, the action of the hormone is characterized by a diverse variety of effects, including changes in vesicle trafficking, stimulation of protein kinases and phosphatases, promotion of cellular growth and differentiation, and activation, or in some cases, repression of transcription. The diverse mechanisms involved in these varied downstream effects suggest that insulin action must involve multiple signaling pathways that diverge at or near the receptor. In this regard, the receptor catalyzes the phosphorylation of several substrates, including the insulin receptor substrate (IRS)* proteins, $^{(2)} \mathrm{GAB}-1,{ }^{(3,4)} \mathrm{Shc}^{(5)}$ and c$\mathrm{Cbl}^{(6)}$ (see Fig. 1). Each of these substrates recruits a distinct subset of signaling protein containing $\mathrm{SH} 2$ domains, in a phosphotyrosine-dependent manner. ${ }^{(2,7,8)}$ Once phosphorylated, the substrate Shc interacts with the adapter protein Grb2, leading to activation of the Ras/Raf/Map kinase pathway. ${ }^{(9)}$ GAB-1 phosphorylation also plays a role in MAP kinase activation, via the tyrosine phosphatase SHP-2. ${ }^{(10-12)}$ Although there are multiple pathways for the activation of MAP kinase, the enzyme is similarly activated by other growth factors that are not insulinomimetic, and is neither necessary nor sufficient for the metabolic actions of insulin. ${ }^{(13,14)}$

Most attention in the field of insulin receptor substrates has focused on the IRS family of proteins. The tyrosine phosphorylation of IRS proteins generates docking sites for a number of SH2-containing proteins. ${ }^{(2)}$ The predominant partner, however, seems to be the p85 regulatory subunit of the type $1 \mathrm{~A} \mathrm{PI}$ 3-kinase. ${ }^{(15)} \mathrm{PI}$ 3-kinase catalyzes the formation of phosphatidylinositol-3,4,5-trisphosphate (PI-3,4,5- $\mathrm{P}_{3}$ ), which

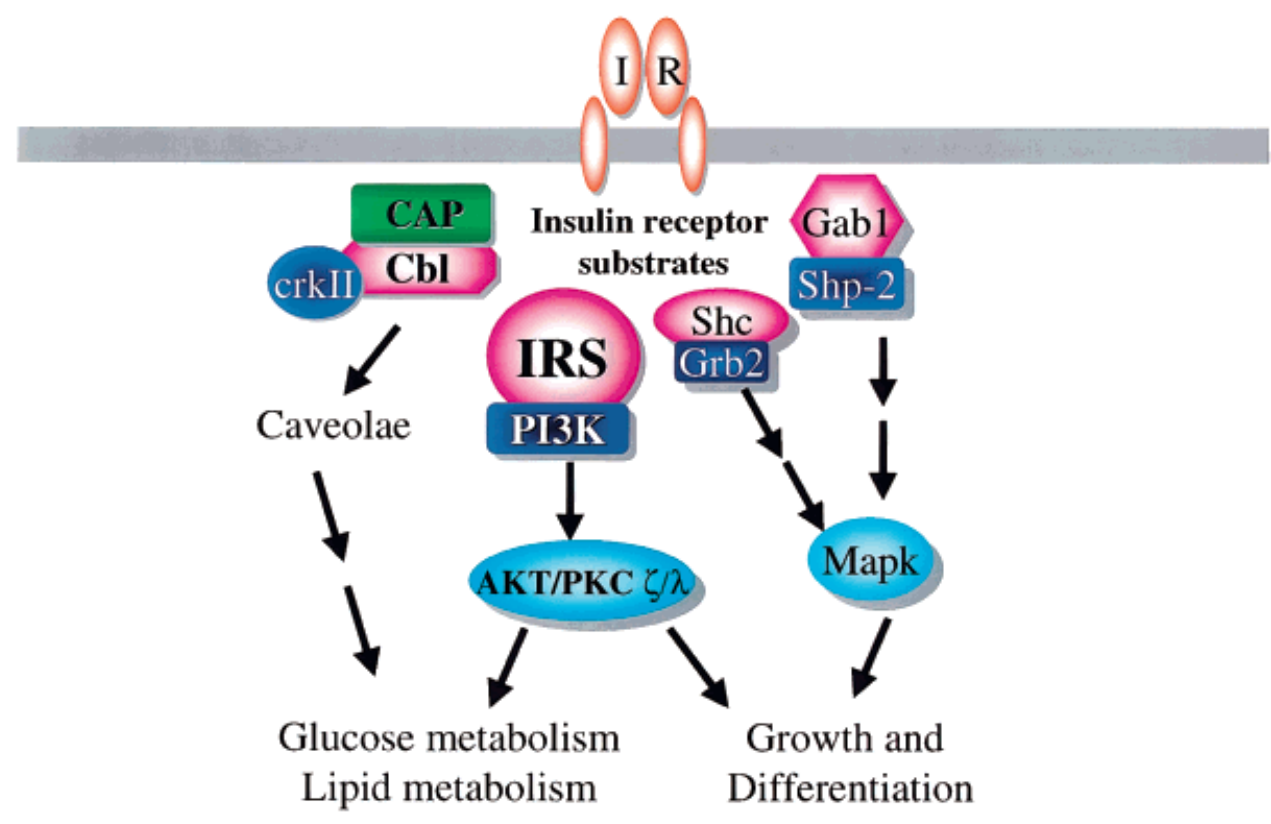

Figure 1. The insulin receptor tyrosine kinase substrates and downstream signaling pathways. Upon insulin binding, the insulin receptor undergoes autophosphorylation on tyrosine residues within the $\beta$-chain of the receptor, recruiting substrate proteins (IRS1-4, Gab1 and Shc) that are tyrosine phosphorylated. Phosphorylation of c-Cbl requires the adapter protein CAP for the recruitment to the insulin receptor. Once phosphorylated, these substrates engage a variety of effector proteins via SH2 domain interactions, including the tyrosine phosphatase SHP2, the adapters crk and Grb2 and the p85 regulatory subunit of PI 3-kinase. Activation or localization of these proteins initiates multiple signaling pathways that regulate diverse functions including metabolic activity, growth and differentiation.

\section{BioEssays 23.3}


serves as an allosteric regulator of the phosphoinositidedependent kinase (PDK). ${ }^{(16)}$ PDK can in turn phosphorylate and activate protein kinase $B$ (PKB/Akt) as well as the atypical protein kinase $\mathrm{C}$ isoforms $\mathrm{PKC} \zeta$ and $\mathrm{PKC} \lambda$. $^{(16,17)}$

Although there is substantial controversy regarding the potential roles of either $\mathrm{PKB} / \mathrm{Akt}$ or $\mathrm{PKC} \zeta / \lambda$ in insulinstimulated Glut4 translocation, PI 3-kinase appears to be essential. Inhibition of PI 3-kinase activity with pharmacological inhibitors such as wortmannin, expression of dominantinterfering mutants, or microinjection of blocking antibodies can completely prevent the stimulation of glucose uptake and Glut4 translocation by insulin. ${ }^{(18-20)}$ Although these data demonstrate the necessity of PI 3-kinase, several lines of evidence indicate that activation of the enzyme is not sufficient. Dramatic overexpression of constitutively active mutants of PI 3-kinase can stimulate Glut4 translocation only partially. ${ }^{(21)}$ Other growth factors, such as PDGF and IL-4, or certain adhesion molecules, stimulate PI 3-kinase to an extent similar to that seen with insulin, but have only a minor effect on glucose uptake and Glut4 translocation. ${ }^{(22,23)}$ In addition, cellpermeable derivatives of $\mathrm{PI}-3,4,5-\mathrm{P}_{3}$ alone cannot mimic the stimulation of glucose uptake by insulin, but can stimulate when cells are pretreated with insulin and a pharmacological inhibitor of PI 3-kinase. ${ }^{(24)}$ Furthermore, several studies have demonstrated that exercise, contraction and hypoxia can all induce glucose uptake and Glut4 translocation in skeletal muscle independent of any detectable PI 3-kinase activation. ${ }^{(25,26)}$ Taken together, these data suggest that insulin must generate at least two independent signals to stimulate glucose transport, one dependent on and another independent of PI 3-kinase. Moreover, the activation of PI 3-kinase by noninsulinomimetic hormones suggests that the second pathway must be unique for insulin. In this review, we will discuss the search for a second signaling pathway, and the potential role of spatial compartmentalization in the specificity of signal transduction in insulin action, particularly regarding the stimulation of glucose transport.

\section{Glucose transport and Glut4}

In mammalian tissues, insulin-stimulated glucose uptake is mediated by the facilitative transporter Glut4, a member of a family of related integral-membrane proteins. ${ }^{(27)}$ Glut4 is highly expressed in skeletal and cardiac muscle and adipose tissue. In the basal state, Glut4 slowly recycles between the plasma membrane and vesicular compartments within the cell, where most of the Glut4 resides. Upon insulin stimulation, Glut4 rapidly translocates to the plasma membrane, through a process of targeted exocytosis. At the same time, Glut4 endocytosis is attenuated, resulting in a dramatic increase in glucose uptake. ${ }^{(28)}$

Although there is substantial evidence that Glut4 exists in specialized vesicles sequestered within the cell, the precise intracellular location and trafficking pathways of these vesicles are unclear. Immunoelectron microscopy has demonstrated the predominant localization of Glut4 in tubulovesicular and vesicular structures, with the some of the protein localized to clathrin-coated vesicles, endosomal structures and the transGolgi network. ${ }^{(28)}$ The Glut4 vesicle appears to be biochemically distinct from the vesicles of the recycling endosomal network, which contain the Glut1 transporter as well as the transferrin and mannose 6-phosphate receptors. ${ }^{(29)}$ Furthermore, the Glut4 compartment is enriched in the v-SNARE (soluble N-ethylmaleimide sensitive factor attachment protein) protein VAMP2 but not the related VAMP3/cellubrevin isoform that is present in the recycling endosome. ${ }^{(28)}$

This specific compartmentalization of Glut4 provides a mechanism by which insulin can stimulate robust translocation of Glut4 to the plasma membrane, while only mildly stimulating the translocation of recycling proteins (Fig. 2). Although the mechanism of intracellular tethering of the Glut4 vesicle in resting cells is unknown, sequestration of Glut4 is dependent on C-terminal sequences in the protein. ${ }^{(30-33)}$ The Glut4 compartment also contains the insulin-responsive aminopeptidase (IRAP). ${ }^{(34,35)}$ Overexpression of the $\mathrm{N}$ terminus of IRAP, which has significant homology to the $C$ terminus of Glut4, results in Glut4 localization to the plasma membrane. These results suggest that both the $C$ terminus of Glut4 and the $\mathrm{N}$ terminus of IRAP contribute to the cytoplasmic sequestration of Glut4 vesicle. However, the cytoplasmic targets of IRAP and Glut4 are unknown. One potential site for Glut4 tethering is the actin cytoskeleton. Insulin stimulates cytoskeletal rearrangement, possibly through the activation of proteins known to regulate actin polymerization, such as effectors of the Rho family of small G-proteins. ${ }^{(36)}$ In this regard, depolymerization of the actin cytoskeleton potently inhibits Glut4 translocation. ${ }^{(37,38)}$ Interestingly, the C-terminal domain of Glut4 can interact with the glycolytic enzyme aldolase. ${ }^{\left({ }^{39)}\right.}$ Aldolase can also bind to actin, and substrates of aldolase can mediate the dissociation of the Glut4-aldolase complex, potentially providing a negative feedback signal for glucose transport. Thus aldolase may mediate the interaction between Glut4 and the cytoskeleton.

Substantial evidence suggests that the plasma membrane target for the GLUT4 vesicle is the t-SNARE, syntaxin 4 (Syn4). ${ }^{(40-43)}$ Thus, the docking of the vesicle may be mediated by the interaction of Syn4 with the Glut4 vesicle vSNARE protein, VAMP2. This interaction is reminiscent of the v-SNARE/t-SNARE interaction seen in synaptic vesicle exocytosis, suggesting that Glut4 exocytosis may occur through mechanisms similar to those proposed for synaptic vesicle transport. ${ }^{(44,45)}$ Several proteins have been demonstrated to bind to Syn4, including SNAP23, ${ }^{(43,46)}$ Munc18c $^{(47,48)}$ and, more recently, Synip, ${ }^{(49)}$ to regulate the docking and fusion of VAMP2-containing GLUT4 vesicles. Among these, Synip has been shown to undergo an insulin-dependent release from Syn4, allowing VAMP2 to bind to the protein. ${ }^{(49)}$ 


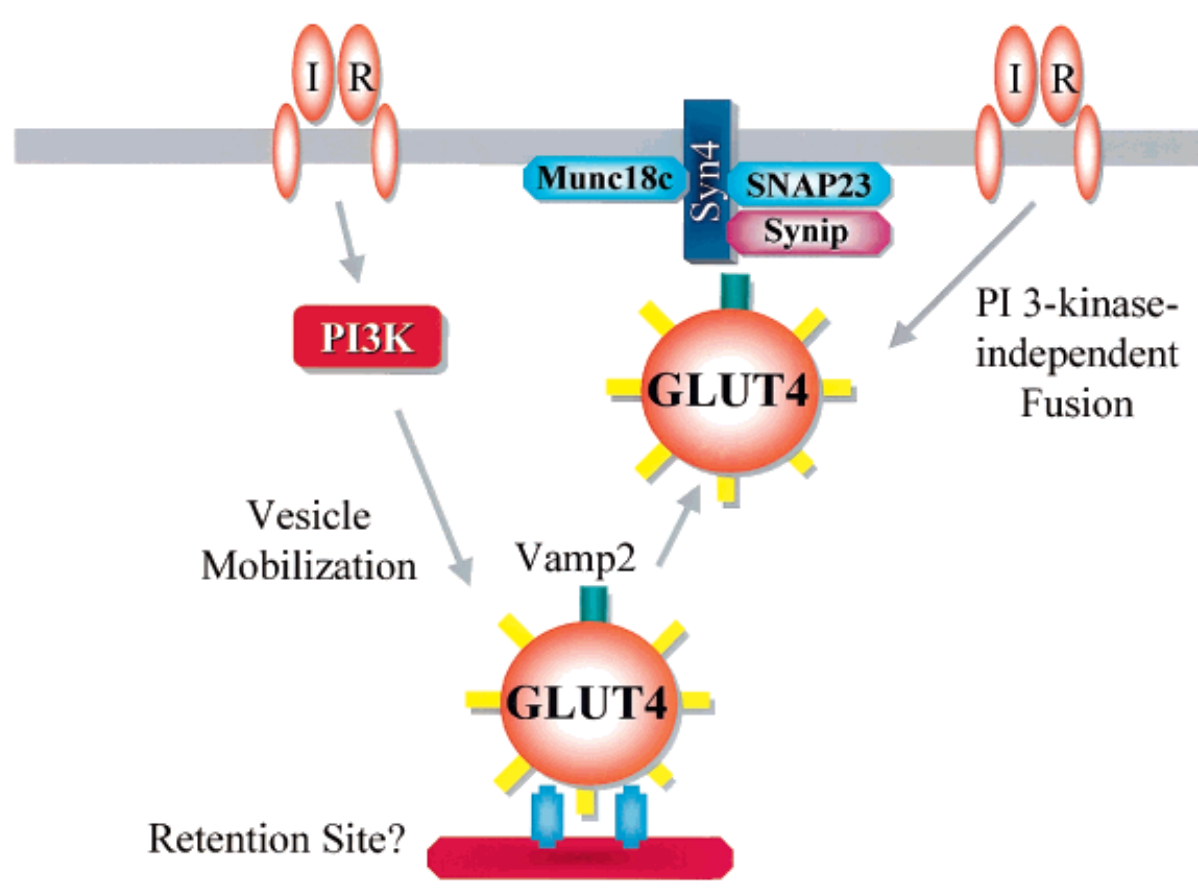

Figure 2. Insulin stimulates glucose transport through PI 3-kinase-dependent and -independent signals that regulate GLUT4containing vesicles. The Glut4 transporter is retained in a specific intracellular vesicle compartment. These Glut4 vesicles (GSV) also contain the v-SNARE protein VAMP2. Insulin causes the release of the GSV from intracellular tethering sites through an unknown pathway initiated by the activation of PI 3-kinase. The docking and fusion of the GSV to the plasma membrane is subsequently mediated through the interaction of the t-SNARE protein syntaxin4 (Syn4) with VAMP2. Other accessory proteins including SNAP23, Munc18c and Synip regulate this docking and fusion process. Evidence suggests that insulin may also regulate that docking and fusion step through the generation of PI3-kinase-independent signals.

\section{Compartmentalized PI 3-kinase activation in the regulation of Glut 4 translocation by insulin}

As mentioned above, it is likely that at least two signaling pathways are required for the stimulation of Glut4 translocation in response to insulin. PI 3-kinase and its downstream effectors are a necessary component of insulin-stimulated Glut4 translocation. Pharmacological inhibitors of PI 3-kinase, such as wortmannin, ${ }^{(18)}$ or microinjection of dominant interfering constructs containing the p85 regulatory subunit of PI 3kinase, ${ }^{(20)}$ block insulin-stimulated Glut4 translocation. Moreover, microinjection of the inositol phosphatase SHIP2 that specifically removes the phosphate from $\mathrm{PIP}_{3}$ blocks insulin action. ${ }^{(50)}$ Overexpression of PI 3-kinase or its downstream targets Akt and PKC $\zeta / \lambda$ in cell culture models increased glucose uptake independent of insulin. ${ }^{(21,51-56)}$ Moreover, in a recent study of type 2 diabetic patients, PI 3-kinase activation was impaired compared to normal subjects. ${ }^{(57)}$

Further evidence for an important role for PI 3-kinase has emerged from studies on the IRS proteins. Mutation of the insulin receptor at tyrosine 960, the docking site of IRS proteins, abolishes insulin-stimulated glucose transport. ${ }^{(58)}$ Mice lacking the IRS-1 protein are insulin resistant, but do not develop diabetes unless crossed to mice in which another signaling molecule has been disrupted. ${ }^{(59-63)}$ Animals lacking IRS-2 exhibit both impaired glucose uptake and diabetes. ${ }^{(64)}$ However, the diabetic phenotype results from a defect in insulin secretion as well as insulin resistance. The mechanism of PI 3-kinase activation via IRS is distinct from that of other tyrosine kinase receptors, such as PDGF and EGF, which recruit PI 3-kinase directly to their receptors. This suggests that the IRS proteins uniquely activate PI 3-kinase via the recruitment of the enzyme to specific sites at or distal to the plasma membrane, perhaps to intracellular membranes. ${ }^{(22,65-67)}$

The formation of $\mathrm{PIP}_{3}$ by $\mathrm{PI}$ 3-kinase leads to the activation of a number of protein kinases. $\mathrm{PIP}_{3}$ appears to mediate the translocation of Akt to the plasma membrane, via its pleckstrin homology $(\mathrm{PH})$ domain. ${ }^{(68)} \mathrm{PKC} \zeta / \lambda$ - and phosphoinositidedependent kinase 1 (PDK1) translocate to the plasma membrane by this same mechanism. Once at the plasma membrane, Akt and $\mathrm{PKC} \zeta / \lambda$ are phosphorylated and activated by PDK1. Although there are data to support an essential role for these kinases in glucose transport, the precise identity of the physiologically relevant kinase remains uncertain. ${ }^{(54,57)}$

\section{BioEssays 23.3}


Also uncertain is whether these protein kinases migrate to new sites upon activation, or whether there is local activation that impacts on Glut4 translocation. Moreover, as of yet, there is no information regarding the protein substrates that might be involved in Glut4 translocation, although there is speculation that this phosphorylation event might regulate the release of the vesicle from intracellular tethering sites.

Other downstream effectors of $\mathrm{PIP}_{3}$ formation have also been implicated in glucose transport. A class of proteins, including GRP1/ARNO, which contain PH domains and Sec7 guanine nucleotide exchange domains for ARF proteins, are recruited to the plasma membrane after insulin stimulation. ${ }^{69-}$

72) The ARF proteins are involved in vesicle movement and may be involved in insulin-stimulated membrane ruffling. Recently, one downstream target of ARF, phospholipase D, was demonstrated to colocalize with the Glut4 vesicle and to potentiate the effects of insulin on Glut4 translocation. ${ }^{(73)}$ It remains unclear, however, whether insulin regulates the activity of phospholipase D. One other potential target for PI 3-kinase is the small GTPase Rab4. Rab4 compartmentalizes with the Glut4 vesicle and redistributes the cytosolic fraction upon insulin stimulation. ${ }^{(74,75)}$ Overexpression of Rab4 leads to an inhibition of insulin-stimulated Glut4 translocation, suggesting that Rab4 is an important regulator of the mobility of the Glut4 vesicle. ${ }^{(74)}$

\section{PI 3-kinase-independent pathways in the regulation of glucose transport}

A potential clue towards identifying the PI 3-kinaseindependent arm of insulin action came from the idea that signal initiation might be segregated into compartments in the plasma membrane. One candidate for such a compartment are caveolae, small invaginations of the plasma membrane that are enriched in lipid-modified signaling proteins, GPIanchored proteins, glycolipids, sphingolipids and cholesterol. ${ }^{(76)}$ Insulin stimulates the tyrosine phosphorylation of caveolin, the major structural protein in caveolae. ${ }^{(77,78)}$ Investigation into this pathway revealed that it was downstream of the phosphorylation of another insulin receptor substrate, the protooncogene c-Cbl. ${ }^{(78)}$ The insulin-stimulated phosphorylation of Cbl occurs only in metabolically responsive cell lines, and not in other fibroblast lines, despite the presence of $\mathrm{Cbl}$ and an active receptor. ${ }^{(6)}$ These findings led us to search for an adapter protein that might recruit $\mathrm{Cbl}$ to the insulin receptor, to explain its phosphorylation only in certain cells. The Cbl-associated protein (CAP) was identified in a twohybrid screen using $\mathrm{Cbl}$ as bait. ${ }^{(79)} \mathrm{CAP}$ contains three carboxyl terminal $\mathrm{SH} 3$ domains, one of which mediates its binding to $\mathrm{Cbl}$. It is expressed predominantly in insulin sensitive tissues and in differentiated 3T3-L1 adipocytes. Interestingly, the $C A P$ gene is upregulated by the insulinsensitizing thiazolidinediones (TZDs). ${ }^{\left({ }^{(0)}\right)}$ TZD activation of the nuclear receptor PPAR $\gamma$ directly activates the transcription of
CAP through a PPAR $\gamma$ response element in the promoter of the CAP gene. ${ }^{(81)}$ Moreover, TZD-stimulated increases in CAP expression lead to a more robust phosphorylation of $\mathrm{Cbl}$ in response to insulin, ${ }^{(80)}$ establishing a potential primary link between TZD-induced insulin sensitization and insulin signal transduction.

The CAP protein recruits $\mathrm{Cbl}$ to the insulin receptor in untreated cells. Upon Cbl phosphorylation, a portion of the Cbl/ CAP complex is released from the receptor and, subsequently, accumulates in a triton-insoluble plasma membrane domain enriched in caveolae or lipid rafts.(78) The insulin-stimulated phosphorylation of $\mathrm{Cbl}$ and its localization to the lipid raft is independent of PI 3-kinase.

The concentration of CAP in lipid rafts appears to result from its association with the caveolar protein flotillin. ${ }^{(82,83)} \mathrm{A}$ dominant interfering mutant of CAP that binds to flotillin, but not $\mathrm{C}-\mathrm{Cbl}$, interferes with this localization of $\mathrm{Cbl}$ to lipid rafts (Fig. 3). Moreover, this mutant specifically blocks insulinstimulated Glut4 translocation and glucose uptake. ${ }^{(83)}$ Once phosphorylated, $\mathrm{Cbl}$ can recruit the $\mathrm{SH}$-containing adapter protein CRKII to the lipid raft, along with the guanine nucleotide exchange factor $\mathrm{C} 3 \mathrm{G}$. Although the precise target of $\mathrm{C} 3 \mathrm{G}$ in the lipid raft is uncertain, recent data suggest that it may activate the rho family protein $\mathrm{TC} 10 .^{(85)}$ This $\mathrm{G}$ protein is expressed in fat and muscle, and can be acutely activated by insulin in a CAP-dependent but PI 3-kinase-independent manner. ${ }^{(84)}$ Although the physiologically relevant effectors that interact with TC10 are unknown, disruption of its activation blocks insulin-stimulated glucose transport and Glut4 translocation. ${ }^{(84)}$

Although the targets of the PI 3-kinase and CAP pathways are uncertain, one likelihood is that they regulate different processes. For example, $\mathrm{PIP}_{3}$-dependent kinases may phosphorylate proteins involved in the tethering of the Glut4 vesicle at intracellular sites, leading to the release and default trafficking of the vesicle to the plasma membrane. On the contrary, the CAP/TC10 pathway may regulate processes involved in the docking and fusion of the vesicle at the plasma membrane. One potential target of this pathway is the syntaxin 4 binding partner Snyip. ${ }^{(49)}$ In the basal state, Synip inhibits the interaction of VAMP2 in the Glut4 vesicle with the syntaxin 4/ SNAP-23 t-SNARE complex in the plasma membrane. Insulin stimulates the disassociation of Synip from syntaxin 4, permitting Syn4-VAMP2 binding, followed by docking and subsequent fusion of the Glut4 vesicle with the plasma membrane. The insulin-stimulated dissociation of Synip from syntaxin 4 is not blocked by wortmannin.

\section{Future prospects}

Although it is clear that multiple signaling pathways are required for the stimulation of glucose transport by insulin, the ultimate targets of these pathways, and the biochemical changes in these targets remain unexplored. Additionally, the 


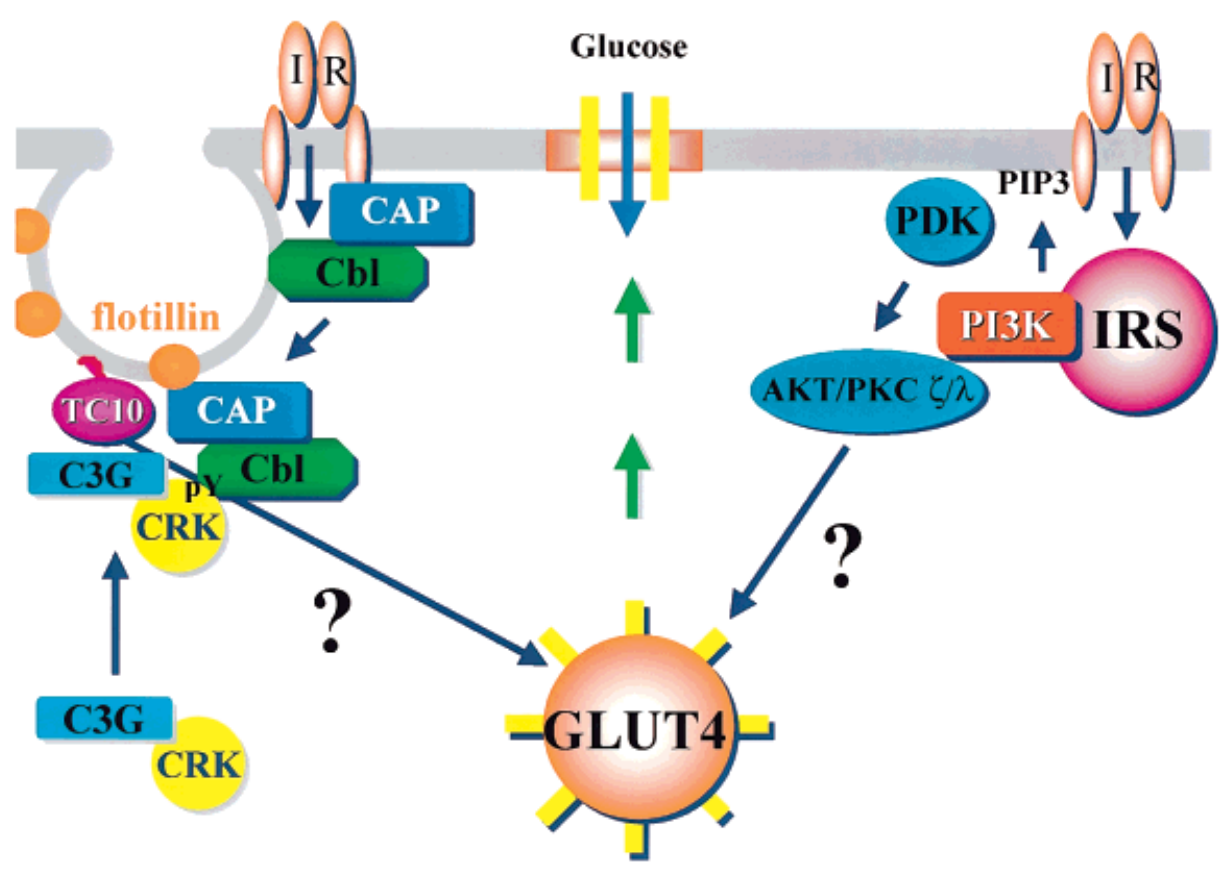

Figure 3. The compartmentalization of insulin-stimulated signaling pathways generates specific activation of GLUT4 translocation. Insulin stimulates PI 3-kinase activity through the tyrosine phosphorylation of IRS proteins, initiating Glut4 translocation. Insulin also stimulates the phosphorylation of $\mathrm{c}-\mathrm{Cbl}$ and translocation of $\mathrm{c}-\mathrm{Cbl}$ to caveolae via the CAP/Flotillin interaction. This allows for the recruitment of the CRKII and its binding partner, the guanine nucleotide exchange factor C3G, to caveolae. The translocation of C3G results in the activation of the small G-protein TC10. Insulin stimulation of both the CAP/c-Cbl translocation to the caveolae and the activation of TC10 occur independently of PI 3-kinase and are required for insulin-stimulated Glut4 translocation.

relative importance of these pathways in different tissues, and their role in mediating other aspects of insulin action on metabolic enzymes, other transport processes, or gene expression have not been evaluated. Most importantly, it will be critical to fully evaluate the structure and functions of the individual components of these pathways in animal models of insulin resistance, as well as in muscle and fat from patients with insulin resistance and type 2 diabetes.

\section{References}

1. Pessin $J$ and Saltiel AR. Signaling pathways in insulin action: molecular targets of insulin resistance. J Clin Invest 2000;106:165-169.

2. White MF. The IRS-signaling system: a network of docking proteins that mediate insulin action. Mol Cell Biochem 1998;182:3-11.

3. Holgado-Madruga M, Emlet DR, Moscatello DK, Godwin AK, Wong AJ. A Grb2-associated docking protein in EGF- and insulin-receptor signaling. Nature 1996;379:560-564.

4. Rocchi S, Tartare-Deckert S, Murdaca J, Holgado-Madruga M, Wong AJ, Van Obberghen E. Determination of Gab1 (Grb2-associated binder-1) interaction with insulin receptor-signaling molecules. Mol Endocrinol 1998; 12:914-923.

5. Sasaoka T, Rose DW, Jhun BH, Saltiel AR, Draznin B, Olefsky JM. Evidence for a functional role of Shc proteins in mitogenic signaling induced by insulin, insulin-like growth factor-1, and epidermal growth factor. J Biol Chem 1994;269:13689-13694.

6. Ribon V, Saltiel AR. Insulin stimulates tyrosine phosphorylation of the proto-oncogene product of $\mathrm{C}-\mathrm{Cb}$ in 3T3-L1 adipocytes. Biochem $\mathrm{J}$ 1997;324:839-845.
7. Sasaoka T, Draznin B, Leitner JW, Langlois WJ, Olefsky JM. Shc is the predominant signaling molecule coupling insulin receptors to activation of guanine nucleotide releasing factor and p21ras-GTP formation. J Biol Chem 1994;269:10734-10738.

8. Ribon V, Hubbell S, Herrera R, Saltiel AR. The product of the cbl oncogene forms stable complexes in vivo with endogenous Crk in a tyrosine phosphorylation-dependent manner. Mol Cell Biol 1996;16:45-52.

9. Downward J. Control of ras activation. Cancer Surv 1996;27:87-100.

10. Cunnick JM, Dorsey JF, Munoz-Antonia T, Mei L, Wu J. Requirement of SHP2 binding to Grb2-associated binder-1 for mitogen-activated protein kinase activation in response to lysophosphatidic acid and epidermal growth factor. J Biol Chem 2000;275:13842-13848.

11. Milarski KL, Saltiel AR. Expression of catalytically inactive Syp phosphatase in 3T3 cells blocks stimulation of mitogen-activated protein kinase by insulin. J Biol Chem 1994;269:21239-21243.

12. Noguchi T, Matozaki T, Horita K, Fujioka Y, Kasuga M. Role of SH-PTP2, a protein-tyrosine phosphatase with Src homology 2 domains, in insulinstimulated Ras activation. Mol Cell Biol 1994;14:6674-6682.

13. Lazar DF, Wiese RJ, Brady MJ, Mastick CC, Waters SB, Yamauchi K, et al. Mitogen-activated protein kinase kinase inhibition does not block the stimulation of glucose utilization by insulin. J Biol Chem 1995;270: 20801-20807.

14. Hausdorff SF, Frangioni JV, Birnbaum MJ. Role of p21ras in insulinstimulated glucose transport in 3T3-L1 adipocytes. J Biol Chem 1994; 269:21391-21394.

15. Alessi DR, Downes CP. The role of PI 3-kinase in insulin action. Biochim Biophys Acta 1998;1436:151-164.

16. Alessi DR, James SR, Downes CP, Holmes AB, Gaffney PR, Reese CB, et al. Characterization of a 3-phosphoinositide-dependent protein kinase which phosphorylates and activates protein kinase Balpha. Curr Biol 1997; 7:261-269 
17. Le Good JA, Ziegler WH, Parekh DB, Alessi DR, Cohen P, Parker PJ Protein kinase $\mathrm{C}$ isotypes controlled by phosphoinositide 3-kinase through the protein kinase PDK1. Science 1998;281:2042-2045.

18. Okada T, Kawano Y, Sakakibara T, Hazeki O, Ui M. Essential role of phosphatidylinositol 3-kinase in insulin-induced glucose transport and antilipolysis in rat adipocytes. Studies with a selective inhibitor wortmannin. J Biol Chem 1994;269:3568-3573.

19. Cheatham B, Vlahos CJ, Cheatham L, Wang L, Blenis J, Kahn CR Phosphatidylinositol 3-kinase activation is required for insulin stimulation of pp70 S6 kinase, DNA synthesis, and glucose transporter translocation. Mol Cell Biol 1994;14:4902-4911.

20. Sharma PM, Egawa K, Huang Y, Martin JL, Huvar I, Boss GR, et al Inhibition of phosphatidylinositol 3-kinase activity by adenovirusmediated gene transfer and its effect on insulin action. J Biol Chem 1998;273:18528-18537.

21. Martin SS, Haruta T, Morris AJ, Klippel A, Williams LT, Olefsky JM Activated phosphatidylinositol 3-kinase is sufficient to mediate actin rearrangement and GLUT4 translocation in 3T3-L1 adipocytes. J Biol Chem 1996;271:17605-17608.

22. Nave BT, Haigh RJ, Hayward AC, Siddle K, Shepherd PR. Compartmentspecific regulation of phosphoinositide 3-kinase by platelet-derived growth factor and insulin in 3T3-L1 adipocytes. Biochem J 1996;318:55-60.

23. Guilherme A, Czech MP. Stimulation of IRS-1-associated phosphatidylinositol 3-kinase and Akt/protein kinase B but not glucose transport by beta1-integrin signaling in rat adipocytes. J Biol Chem 1998;273:33119122

24. Jiang T, Sweeney G, Rudolf MT, Klip A, Traynor-Kaplan A, Tsien RY Membrane-permeant esters of phosphatidylinositol 3,4,5-trisphosphate. J Biol Chem 1998;273:11017-11024

25. Cushman SW, Goodyear LJ, Pilch PF, Ralston E, Galbo H, Ploug T, et al Molecular mechanisms involved in GLUT4 translocation in muscle during insulin and contraction stimulation. Adv Exp Med Biol 1998;441:63-71.

26. Cortright RN, Dohm GL. Mechanisms by which insulin and muscle contraction stimulate glucose transport. Can J Appl Physiol 1997;22 519-530.

27. Olson AL, Pessin JE. Structure, function, and regulation of the mammalian facilitative glucose transporter gene family. Annu Rev Nutr 1996; 16:235-256.

28. Pessin JE, Thurmond DC, Elmendorf JS, Coker KJ, Okada S. Molecular basis of insulin-stimulated GLUT4 vesicle trafficking. Location! Location! Location! J Biol Chem 1999;274:2593-2596.

29. Rea S, James DE. Moving GLUT4: the biogenesis and trafficking of GLUT4 storage vesicles. Diabetes 1997:46:1667-1677.

30. Verhey KJ, Hausdorff SF, Birnbaum MJ. Identification of the carboxy terminus as important for the isoform-specific subcellular targeting of glucose transporter proteins. J Cell Biol 1993;123:137-147.

31. Marsh BJ, Alm RA, Mclntosh SR, James DE. Molecular regulation of GLUT-4 targeting in 3T3-L1 adipocytes. J Cell Biol 1995;130:1081-1091.

32. Haney PM, Levy MA, Strube MS, Mueckler M. Insulin-sensitive targeting of the GLUT4 glucose transporter in L6 myoblasts is conferred by its COOH-terminal cytoplasmic tail. J Cell Biol 1995;129:641-658.

33. Czech MP, Chawla A, Woon CW, Buxton J, Armoni M, Tang W, et al Exofacial epitope-tagged glucose transporter chimeras reveal $\mathrm{COOH}$ terminal sequences governing cellular localization. J Cell Biol 1993;123: $127-135$.

34. Kandror KV, Pilch PF. gp160, a tissue-specific marker for insulin-activated glucose transport. Proc Natl Acad Sci U S A 1994;91:8017-8021.

35. Keller SR, Scott HM, Mastick CC, Aebersold R, Lienhard GE. Cloning and characterization of a novel insulin-regulated membrane aminopeptidase from Glut4 vesicles J Biol Chem 1995;270:23612-23618.

36. Tsakiridis T, Tong P, Matthews B, Tsiani E, Bilan PJ, Klip A, et al. Role of the actin cytoskeleton in insulin action. Microsc Res Tech 1999;47:79-92.

37. Omata W, Shibata H, Li L, Takata K, Kojima I. Actin filaments play a critical role in insulin-induced exocytotic recruitment but not in endocytosis of GLUT4 in isolated rat adipocytes. Biochem J 2000;346 Pt 2:321-328.

38. Tsakiridis T, Vranic M, Klip A. Disassembly of the actin network inhibits insulin-dependent stimulation of glucose transport and prevents recruitment of glucose transporters to the plasma membrane. J Biol Chem 1994;269:29934-29942
39. Kao AW, Noda Y, Johnson JH, Pessin JE, Saltiel AR. Aldolase mediates the association of F-actin with the insulin-responsive glucose transporter GLUT4. J Biol Chem 1999;274:17742-17747.

40. Volchuk A, Wang Q, Ewart HS, Liu Z, He L, Bennett MK, et al. Syntaxin 4 in 3T3-L1 adipocytes: regulation by insulin and participation in insulindependent glucose transport. Mol Biol Cell 1996;7:1075-1082.

41. Olson AL, Knight JB, Pessin JE. Syntaxin 4, VAMP2, and/or VAMP3/ cellubrevin are functional target membrane and vesicle SNAP receptors for insulin-stimulated GLUT4 translocation in adipocytes. Mol Cell Biol 1997; 17:2425-2435.

42. Cheatham B, Volchuk A, Kahn CR, Wang L, Rhodes CJ, Klip A. Insulinstimulated translocation of GLUT4 glucose transporters requires SNAREcomplex proteins. Proc Natl Acad Sci U S A 1996;93:15169-15173.

43. Rea S, Martin LB, Mclntosh S, Macaulay SL, Ramsdale T, Baldini G, et al. Syndet, an adipocyte target SNARE involved in the insulin-induced translocation of GLUT4 to the cell surface. J Biol Chem 1998;273:18784-18792.

44. Bennett MK. Ca ${ }^{2+}$ and the regulation of neurotransmitter secretion. Curr Opin Neurobiol 1997;7:316-322.

45. Goda Y. SNAREs and regulated vesicle exocytosis [comment]. Proc Natl Acad Sci U S A 1997;94:769-772.

46. Kawanishi M, Tamori Y, Okazawa H, Araki S, Shinoda H, Kasuga M. Role of SNAP23 in insulin-induced translocation of GLUT4 in 3T3-L1 adipocytes. Mediation of complex formation between syntaxin4 and VAMP2. J Biol Chem 2000;275:8240-8247.

47. Thurmond DC, Ceresa BP, Okada S, Elmendorf JS, Coker K, Pessin JE. Regulation of insulin-stimulated GLUT4 translocation by Munc18c in 3T3L1 adipocytes. J Biol Chem 1998;273:33876-33883.

48. Thurmond DC, Kanzaki M, Khan AH, Pessin JE. Munc18c function is required for insulin-stimulated plasma membrane fusion of GLUT4 and insulin-responsive amino peptidase storage vesicles. Mol Cell Biol 2000;20:379-388

49. Min J, Okada S, Kanzaki M, Elmendorf JS, Coker KJ, Ceresa BP, et al. Synip: a novel insulin-regulated syntaxin 4-binding protein mediating GLUT4 translocation in adipocytes. Mol Cell 1999;3:751-760.

50. Vollenweider P, Clodi M, Martin SS, Imamura T, Kavanaugh WM, Olefsky JM. An SH2 domain-containing 5' inositolphosphatase inhibits insulininduced GLUT4 translocation and growth factor-induced actin filament rearrangement. Mol Cell Biol 1999;19:1081-1091.

51. Kohn AD, Summers SA, Birnbaum MJ, Roth RA. Expression of a constitutively active Akt Ser/Thr kinase in 3T3-L1 adipocytes stimulates glucose uptake and glucose transporter 4 translocation. J Biol Chem 1996;271:31372-31378.

52. Cong LN, Chen H, Li Y, Zhou L, McGibbon MA, Taylor SI, et al. Physiological role of Akt in insulin-stimulated translocation of GLUT4 in transfected rat adipose cells. Mol Endocrinol 1997;11:1881-1890.

53. Hajduch E, Alessi DR, Hemmings BA, Hundal HS. Constitutive activation of protein kinase $B$ alpha by membrane targeting promotes glucose and system A amino acid transport, protein synthesis, and inactivation of glycogen synthase kinase 3 in L6 muscle cells. Diabetes 1998;47:10061013

54. Kotani K, Ogawa W, Matsumoto M, Kitamura T, Sakaue H, Hino Y, et al. Requirement of atypical protein kinase clambda for insulin stimulation of glucose uptake but not for Akt activation in 3T3-L1 adipocytes. Mol Cell Biol 1998;18:6971-6982

55. Bandyopadhyay G, Standaert ML, Kikkawa U, Ono Y, Moscat J, Farese RV. Effects of transiently expressed atypical (zeta, lambda), conventional (alpha, beta) and novel (delta, epsilon) protein kinase $\mathrm{C}$ isoforms on insulin-stimulated translocation of epitope-tagged GLUT4 glucose transporters in rat adipocytes: specific interchangeable effects of protein kinases C-zeta and C-lambda. Biochem J 1999;337:461-470.

56. Etgen GJ, Valasek KM, Broderick CL, Miller AR. In vivo adenoviral delivery of recombinant human protein kinase C-zeta stimulates glucose transport activity in rat skeletal muscle. J Biol Chem 1999;274:22139-22142.

57. Kim YB, Nikoulina SE, Ciaraldi TP, Henry RR, Kahn BB. Normal insulindependent activation of Akt/protein kinase B, with diminished activation of phosphoinositide 3-kinase, in muscle in type 2 diabetes [In Process Citation]. J Clin Invest 1999;104:733-741.

58. White MF, Livingston JN, Backer JM, Lauris V, Dull TJ, Ullrich A, et al. Mutation of the insulin receptor at tyrosine 960 inhibits signal transmission but does not affect its tyrosine kinase activity. Cell 1988;54:641-649. 
59. Araki E, Lipes MA, Patti ME, Bruning JC, Haag B, 3rd, Johnson RS, et al. Alternative pathway of insulin signalling in mice with targeted disruption of the IRS-1 gene [see comments]. Nature 1994;372:186-190.

60. Tamemoto H, Kadowaki T, Tobe K, Yagi T, Sakura H, Hayakawa T, et al. Insulin resistance and growth retardation in mice lacking insulin receptor substrate-1. Nature 1994;372:182-186.

61. Kido Y, Burks DJ, Withers D, Bruning JC, Kahn CR, White MF, et al. Tissue-specific insulin resistance in mice with mutations in the insulin receptor, IRS-1, and IRS-2. J Clin Invest 2000;105:199-205.

62. Terauchi $\mathrm{Y}$, Iwamoto $\mathrm{K}$, Tamemoto $\mathrm{H}$, Komeda K, Ishii C, Kanazawa $\mathrm{Y}$, et al. Development of non-insulin-dependent diabetes mellitus in the double knockout mice with disruption of insulin receptor substrate-1 and beta cell glucokinase genes. Genetic reconstitution of diabetes as a polygenic disease. J Clin Invest 1997;99:861-866.

63. Bruning JC, Winnay J, Bonner-Weir S, Taylor SI, Accili D, Kahn CR. Development of a novel polygenic model of NIDDM in mice heterozygous for IR and IRS-1 null alleles. Cell 1997;88:561-572.

64. Withers DJ, Gutierrez JS, Towery H, Burks DJ, Ren JM, Previs S, et al. Disruption of IRS-2 causes type 2 diabetes in mice. Nature 1998;391: 900-904.

65. Kelly KL, Ruderman NB. Insulin-stimulated phosphatidylinositol 3-kinase. Association with a $185-\mathrm{kDa}$ tyrosine-phosphorylated protein (IRS-1) and localization in a low density membrane vesicle. J Biol Chem 1993;268: 4391-4398.

66. Inoue $\mathrm{G}$, Cheatham B, Emkey R, Kahn CR. Dynamics of insulin signaling in 3T3-L1 adipocytes. Differential compartmentalization and trafficking of insulin receptor substrate (IRS)-1 and IRS-2. J Biol Chem 1998;273: $11548-11555$

67. Clark SF, Martin S, Carozzi AJ, Hill MM, James DE. Intracellular localization of phosphatidylinositide 3-kinase and insulin receptor substrate-1 in adipocytes: potential involvement of a membrane skeleton. J Cell Biol 1998;140:1211-1225.

68. Corvera S, Czech MP. Direct targets of phosphoinositide 3-kinase products in membrane traffic and signal transduction. Trends Cell Biol 1998;8:442-446

69. Tanaka K, Imajoh-Ohmi S, Sawada T, Shirai R, Hashimoto Y, Iwasaki S, et al A target of phosphatidylinositol 3,4,5-trisphosphate with a zinc finger motif similar to that of the ADP-ribosylation-factor GTPase-activating protein and two pleckstrin homology domains. Eur J Biochem 1997;245:512-519.

70. Klarlund JK, Rameh LE, Cantley LC, Buxton JM, Holik JJ, Sakelis C, et al. Regulation of GRP1-catalyzed ADP ribosylation factor guanine nucleotide exchange by phosphatidylinositol 3,4,5-trisphosphate. J Biol Chem 1998;273:1859-1862.

71. Frank S, Upender S, Hansen SH, Casanova JE. ARNO is a guanine nucleotide exchange factor for ADP-ribosylation factor 6. J Biol Chem 1998;273:23-27.
72. Venkateswarlu K, Oatey PB, Tavare JM, Cullen PJ. Insulin-dependent translocation of ARNO to the plasma membrane of adipocytes requires phosphatidylinositol 3-kinase. Curr Biol 1998;8:463-466.

73. Emoto M, Klarlund JK, Waters SB, Hu V, Buxton JM, Chawla A, et al. A role for phospholipase D in GLUT4 glucose transporter translocation. J Biol Chem 2000;275:7144-7151.

74. Cormont M, Bortoluzzi MN, Gautier N, Mari M, van Obberghen E, Le Marchand-Brustel Y. Potential role of Rab4 in the regulation of subcellular localization of Glut4 in adipocytes. Mol Cell Biol 1996;16: 6879-6886

75. Shibata H, Omata W, Kojima I. Insulin stimulates guanine nucleotide exchange on Rab4 via a wortmannin-sensitive signaling pathway in rat adipocytes. J Biol Chem 1997;272:14542-14546.

76. Smart EJ, Graf GA, McNiven MA, Sessa WC, Engelman JA, Scherer PE, et al. Caveolins, liquid-ordered domains, and signal transduction. Mo Cell Biol 1999;19:7289-7304.

77. Mastick CC, Brady MJ, Saltiel AR. Insulin stimulates the tyrosine phosphorylation of caveolin. J Cell Biol 1995;129:1523-1531.

78. Mastick CC, Saltiel AR. Insulin-stimulated tyrosine phosphorylation of caveolin is specific for the differentiated adipocyte phenotype in 3T3-L1 cells. J Biol Chem 1997;272:20706-20714.

79. Ribon V, Printen JA, Hoffman NG, Kay BK, Saltiel AR. A novel, multifuntional $\mathrm{c}-\mathrm{Cb}$ binding protein in insulin receptor signaling in 3T3L1 adipocytes. Mol Cell Biol 1998;18:872-879.

80. Ribon V, Johnson JH, Camp HS, Saltiel AR. Thiazolidinediones and insulin resistance: peroxisome proliferatoractivated receptor gamma activation stimulates expression of the CAP gene. Proc Natl Acad Sci USA 1998;95:14751-14756.

81. Baumann CA, Chokshi N, Saltiel AR, Ribon V. Cloning and characterization of a functional peroxisome proliferator activator receptor-gammaresponsive element in the promoter of the CAP gene. J Biol Chem 2000;275:9131-9135

82. Bickel PE, Scherer PE, Schnitzer JE, Oh P, Lisanti MP, Lodish HF. Flotillin and epidermal surface antigen define a new family of caveolaeassociated integral membrane proteins. J Biol Chem 1997;272:1379313802.

83. Baumann CA, Ribon V, Kanzaki M, Thurmond DC, Mora S, Shigematsu S, Bickel PE, Pessin JE, Saltiel, AR. CAP defines a second signaling pathway for insulin-stimulated glucose transport. Nature 2000;407:202-207.

84. Chiang SH, Baumann CA, Kanzaki, M, Thurmond DC, Neudauer CL, Macara IG, Pessin JE, Saltiel, AR. Insulin-stimulated GLUT4 translocation requires the CAP dependent activation of the small GTP binding protein TC10 (in press)

85. Drivas GT, Shih A, Coutavas E, Rush MG, D'Eustachio P. Characterization of four novel ras-like genes expressed in a human teratocarcinoma cell line. Mol Cell Biol 1990;10:1793-1798.

\section{BioEssays 23.3}

